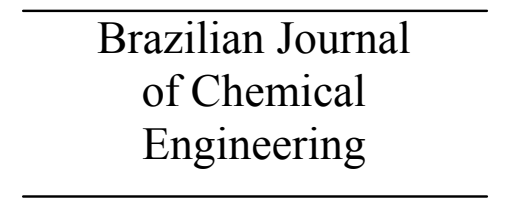

ISSN 0104-6632

Printed in Brazil

www.abeq.org.br/bjche

Vol. 28, No. 02, pp. 273 - 284, April - June, 2011

\title{
NUMERICAL STUDY ON HYGROSCOPIC MATERIAL DRYING IN PACKED BED
}

\author{
M. Stakić ${ }^{1 *}$, M. Banjac ${ }^{2}$ and T. Urošević ${ }^{3}$ \\ ${ }^{1}$ University of Belgrade, Institute of Nuclear Sciences "Vinča", \\ Phone: +381 11340 8365, +381 64952 3052, P.O. Box 522, 11001, Belgrade, Serbia. \\ E-mail: stakicm@yahoo.com \\ ${ }^{2}$ University of Belgrade, Faculty of Mechanical Engineering, Belgrade, Serbia. \\ ${ }^{3}$ University of Belgrade, Faculty of Agriculture, Belgrade, Serbia.
}

(Submitted: November 2, 2009 ; Revised: January 27, 2011 ; Accepted: February 2, 2011)

\begin{abstract}
The paper addresses numerical simulation for the case of convective drying of hygroscopic material in a packed bed, analyzing agreement between the simulated and the corresponding experimental results. In the simulation model of unsteady simultaneous one-dimensional heat and mass transfer between gas phase and dried material, it is assumed that the gas-solid interface is at thermodynamic equilibrium, while the drying rate of the specific product is calculated by applying the concept of a "drying coefficient". Model validation was done on the basis of the experimental data obtained with potato cubes. The obtained drying kinetics, both experimental and numerical, show that higher gas (drying agent) velocities (flow-rates), as well as lower equivalent grain diameters, induce faster drying. This effect is more pronounced for deeper beds, because of the larger amount of wet material to be dried using the same drying agent capacity.

Keywords: Heat and mass transfer; Mathematical model; Simulation.
\end{abstract}

\section{INTRODUCTION}

Digital computers and numerical mathematics are widely used for the purpose of solving heat and mass balance equations for chemical engineering processes. Results obtained on the basis of a reliable mathematical model and numerical analysis enable prediction of the relevant process parameters required for design of a particular device and optimization of the process itself. A good model (numerical simulation) can successfully substitute lengthy and expensive experimental research.

During the drying of non-hygroscopic and/or hygroscopic capillary-porous materials, the first part of the drying curve has a similar form (Fig. 1) (Keey, 1972). In the case of the hygroscopic capillary-porous material, the drying rate drops more sharply since, deep inside the material, the sorption state is ensured, i.e., when the partial pressure of water vapor at this place becomes less than the partial pressure of free water. This drying period ends at the moment when all the material layers are in the hygroscopic regime (the second critical point appears).

Contemporary market demands require process equipment fully optimized with respect to operating conditions. This is especially the case with dryers, because of their significant energy consumption. The most convenient method of optimization is by simulation based on mathematical models and on reliable computer programs. One of the first models for cross-flow packed bed dryers, the one-phase model proposed by Thompson (1970), was significant at that time for dryer design. Becker et al. (1971) modified the so-called distributed parameter model (DPM). This model was further developed by Douglas et al. (1994) and compared with experimental data. The so-called Michigan State cross-flow dryer model (MSU) proposed by BakkerArkema et al. (1978) leads to similar results when similar equilibrium moisture content values are used. The numerical procedure for the MSU model relies on an explicit method of finite differences, which

*To whom correspondence should be addressed 
requires certain stability conditions between the step sizes of the time and space variables. In contrast to previous work, Dalpasquale et al. (2008) established a stable implicit method based on backward finite differences, in both space and time variables, taking into account some specific empirical aspects of fixed-bed drying.

Recent models by Sitompul et al. (2001) and Istadi and Sitompul (2002) take into account transport phenomena within the deep-bed and in the spherical grains. Moreover, the effect of air velocity distribution (pressure field) on the drying process was studied. Basically the same model (Sitompul et al., 2003) was used for a different dryer geometry (large diameter column). Special attention on the interfacial conditions was placed by Herman et al. (2001). The authors claim that their model can be used to consider the dominant phenomenon (internal or external) in a drying process. The governing equations of the models were solved numerically by the finite difference method. Izadifar et al. (2006) modeled packed bed drying using the local volume averaging (LVA) approach, with local thermal equilibrium in each elementary volume in order to derive transient heat and mass transfer equations, solved by means of an implicit numerical method. Recently, a MATHLAB simulation software (SAPGD) was presented by Wang et al. (2004).

The results of the calculations obtained by all

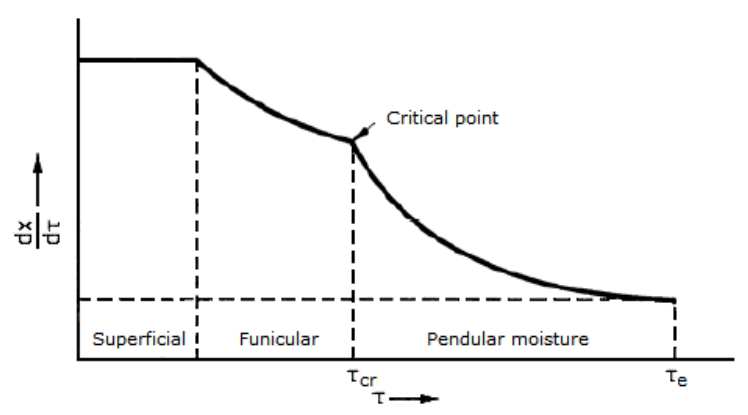

(a) models mentioned are only for the case of a singlepass gas flow through the packed bed. It is apparent that different theoretical approaches (thin layer model, stationary bed models, etc.) can be applied to define the governing equations of the packed bed drying model. Several corresponding numerical methods (finite element, finite differences, finite volume, etc.) can be used for discretization of the differential equations defining conservation of the relevant variables (moisture, enthalpy, etc.). In order to calculate drying rates under different conditions (very difficult by theory alone), two concepts are generally used nowadays to estimate material-specific kinetics, such as the "characteristic drying curve" (van Meel, 1958) or the "drying coefficient" (Luikov, 1968).

The purpose of this work is to apply a model based on the material-specific kinetics ("drying coefficient") and equilibrium data (moisture isotherms), derived from original small-scale drying experiments and expressed in suitable forms, utilizing a control volume numerical method to solve the coupled differential equations. Some of the results obtained for numerical simulation of the convective drying of hygroscopic material (potato cubes) in a packed bed are shown in this paper. The specific approach used to define the drying equation, although discussed in some previous publications (Stakić, 1997, Stakić and Tsotsas, 2005), is also explained in this paper.

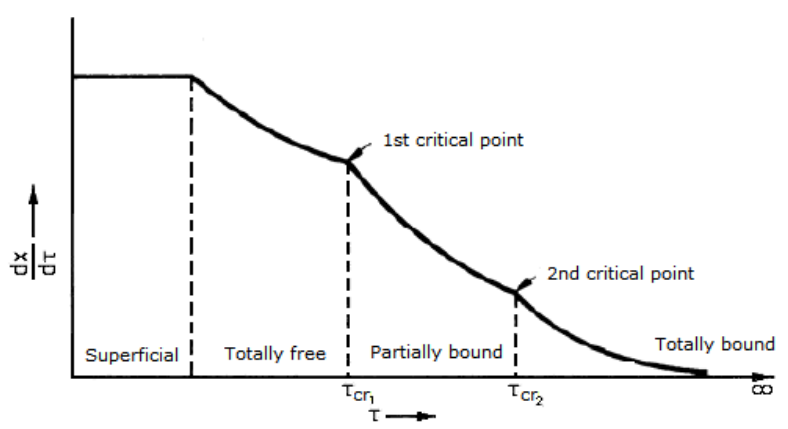

(b)

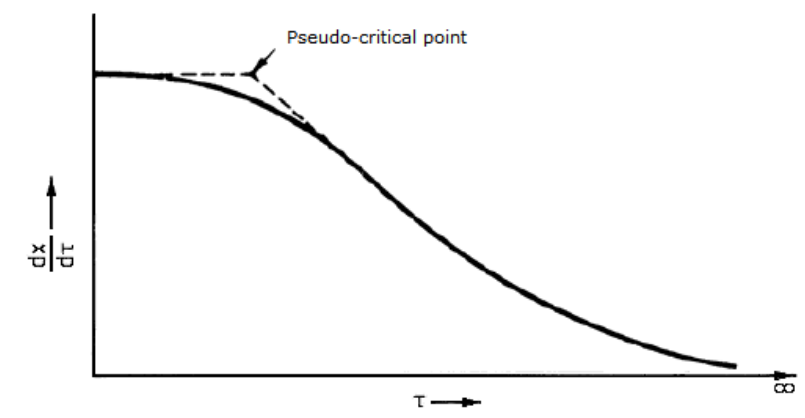

(c)

Figure 1: Variation of drying rate with time in the case of: (a) non-hygroscopic capillary-porous materials, (b) hygroscopic capillary-porous materials, (c) hygroscopic non-porous materials. 


\section{MATHEMATICAL MODEL}

Consideration is given to the convective drying as an unsteady problem of heat and mass transfer caused by fluid flow (drying agent flow) through the bed of particulate solids. The differential equation describing the conservation of a general dependent variable $\Phi$, in the case of an unsteady problem, can be written in a generalized form after Patankar (1980):

$$
\frac{\partial}{\partial \tau}(\mathrm{M} \cdot \Phi)+\operatorname{div}(\overrightarrow{\mathrm{u}} \cdot \mathrm{M} \cdot \Phi)=\operatorname{div}\left(\Gamma_{\Phi} \cdot \operatorname{grad} \Phi\right)+\mathrm{S}_{\Phi}
$$

The terms in Equation (1) are called: the "unsteady term", the "convection term", the "diffusion term", and the "source term". Interphase transport laws must be incorporated into the "source term", representing generation and dissipation of the variable $\Phi$. Expressions for $\Gamma_{\Phi}$ and $S_{\Phi}$ depend on the physical meaning of the variable $\Phi$. In convective drying, moisture content and enthalpy (temperature) of the material being dried, as well as humidity and enthalpy (temperature) of the used drying agent, are particular cases of the general dependent variable to be determined.

The basic assumptions adopted in the mathematical model describing the unsteady simultaneous one-dimensional heat and mass transfer between a gas phase and a material during convective drying in a packed bed are:

- Drying parameters vary in one dimension, namely in the direction of gas flow (usually vertical), and only changes of the parameters in this direction will be discussed;

- All solids are of the same size, shape, and density at anyone moment of time;

- The gas-solid interface is at thermodynamic equilibrium;

- The drying rate (evaporated moisture flux) of the specific product is calculated by applying the concept of a "drying coefficient";

- Heat transfer inside the solids (temperature gradient) is neglected;

- Dispersion of mass or heat in the considered direction of gas flow is neglected.

On the basis of Eq. (1) and with the assumptions mentioned above, the following system of partial differential equations can be used to describe heat and mass balances (with the symbols defined in the Nomenclature section):

Conservation of moisture, gas:

$\frac{\partial}{\partial \tau}\left(M_{G, d} \cdot Y\right)+\frac{\partial}{\partial z}\left(u_{G} \cdot M_{G, d} \cdot Y\right)=+S_{M} \cdot$ with

$Y(0, \tau)=Y_{\text {in }}$, for $\mathrm{Z}=0$ and

$\tau \geq 0, Y(z, 0)=Y_{0}(z)$, for $0 \leq z \leq h$ and $\tau=0$.

Conservation of moisture, solids:

$\frac{\partial}{\partial \tau}\left(M_{S, d} \cdot X\right)+\frac{\partial}{\partial z}\left(u_{S} \cdot M_{S, d} \cdot X\right)=-S_{M} \cdot$

with

$\mathrm{X}(\mathrm{z}, 0)=\mathrm{X}_{0}$, for $0 \leq \mathrm{z} \leq \mathrm{h}$ and $\tau=0$.

Conservation of gas enthalpy:

$\frac{\partial}{\partial \tau}\left(M_{G, d} \cdot c_{G} \cdot T_{G}\right)+\frac{\partial}{\partial z}\left(u_{G} \cdot M_{G, d} \cdot c_{G} T_{G}\right)=$
$\alpha_{S, G} \cdot a_{b} \cdot V \cdot\left(T_{S}-T_{G}\right)+c_{v} \cdot\left(T_{G}-T_{S}\right) \cdot S_{M}$,

where

$\mathrm{c}_{\mathrm{G}}=\mathrm{c}_{\mathrm{G}, \mathrm{d}}+\mathrm{c}_{\mathrm{v}} \cdot \mathrm{Y}$,

with

$\mathrm{T}_{\mathrm{G}}(0, \tau)=\mathrm{T}_{\mathrm{G}, \text { in }}$, for $\mathrm{z}=0$ and

$\tau \geq 0, \mathrm{~T}_{\mathrm{G}}(\mathrm{z}, 0)=\mathrm{Y}_{\mathrm{G}, 0}(\mathrm{z})$, for $0 \leq \mathrm{z} \leq \mathrm{h}$ and $\tau=0$.

Conservation of solids enthalpy:

$$
\begin{aligned}
& \frac{\partial}{\partial \tau}\left(M_{S, d} \cdot c_{S} \cdot T_{S}\right)+\frac{\partial}{\partial z}\left(u_{S} \cdot M_{S, d} \cdot c_{S} \cdot T_{S}\right)= \\
& \alpha_{S, G} \cdot a_{b} \cdot V \cdot\left(T_{G}-T_{S}\right)-r \cdot S_{M}
\end{aligned},
$$

where

$\mathrm{c}_{\mathrm{S}}=\mathrm{c}_{\mathrm{S}, \mathrm{d}}+\mathrm{c}_{\mathrm{w}} \cdot \mathrm{X}$

with

$\mathrm{T}_{\mathrm{S}}(\mathrm{z}, 0)=\mathrm{T}_{\mathrm{S}, 0}$, for $0 \leq \mathrm{z} \leq \mathrm{h}$ and $\tau=0$.

Equation of continuity for gas phase:

$\frac{\partial}{\partial \tau}\left(\mathrm{M}_{\mathrm{G}}\right)+\frac{\partial}{\partial \mathrm{z}}\left(\mathrm{u}_{\mathrm{G}} \cdot \mathrm{M}_{\mathrm{G}}\right)=\mathrm{S}_{\mathrm{M}} \cdot$ 
The gas velocity through the packed bed of solids (interstitial velocity) is $\mathrm{u}_{\mathrm{G}}=\mathrm{u}_{\mathrm{G}, \text { in }} / \psi$, where $\mathrm{u}_{\mathrm{G}, \text { in }}$ stands for the gas velocity in a free cross section of the apparatus (superficial velocity). Because in the present case of a packed bed there is no movement of the solids, the solids velocity is set to $\mathrm{u}_{\mathrm{S}}=0$. Notice that $\Gamma_{\Phi}$ is also set to zero in the transition from Equation (1) to Equations (2)-(6) (dispersion neglected in the direction of flow).

In order to define the mass source, $\mathrm{S}_{\mathrm{M}}$, which is, for the case of convective drying, the evaporated moisture flow-rate, the system of coupled partial differential Equations (2)-(6) has to be completed with a drying rate equation. Prediction of falling-rate drying kinetics by theory alone is very difficult, and accurate small-scale experiments are required instead (Hirschmann et al., 1998). It is possible to estimate drying rates under different conditions by concepts such as a "characteristic drying curve" (van Meel, 1958) or the "drying coefficient" (Luikov, 1968, Milojević and Stefanović, 1982, etc.). For this purpose, the concept of a "drying coefficient" is used in the present work. Within the scope of the "drying coefficient" concept, the transport phenomena inside and outside the solids are considered separately. The reason for this is the fact that, during convective drying, two types of mass transfer resistances exist, due to:

- Moisture transport from the interior to the surface of the solids;

- Moisture convection from the surface of the solids to the surrounding gas.

Internal moisture transport is a more complex problem, due to the variety of mechanisms involved (capillarity, diffusion, thermal diffusion, bulk and molecular flow, surface diffusion) that depend on the specific structure of the product.

The moisture flow-rate from the interior to the surface of the solids is, therefore, expressed empirically as:

$\mathrm{S}_{\mathrm{M}}=\mathrm{M}_{\mathrm{S}, \mathrm{d}} \cdot \mathrm{k}_{\mathrm{i}} \cdot\left(\mathrm{X}_{\mathrm{sf}, \mathrm{eq}}-\mathrm{X}\right)$,

where $\mathrm{k}_{\mathrm{i}}$ is the internal moisture transport coefficient (the already mentioned "drying coefficient").

On the other hand, all the moisture transported from the solids' interior to its surface has to be subsequently transferred to the surrounding gas. It is assumed that the solid surface and the gas in its immediate vicinity are at hygroscopic equilibrium with each other. Therefore, the evaporated moisture flow-rate can also be expressed as:

$$
\mathrm{S}_{\mathrm{M}}=\mathrm{M}_{\mathrm{G}, \mathrm{d}} \cdot \beta_{\mathrm{S}, \mathrm{G}} \cdot \mathrm{a}_{\mathrm{b}} \cdot\left(\mathrm{Y}-\mathrm{Y}_{\mathrm{eq}}\right) .
$$

Since Equations (7) and (8) are mutually coupled by equilibrium, they have to be solved simultaneously.

The unknown variables $Y_{\text {eq }}$ and $X_{\text {sf,eq }}$ (equilibrium gas and solids moisture content at the solid surface, respectively) must fulfill the condition of hygroscopic equilibrium for the specific moisture on the specific product, in our present case for water on coal. The empirical drying coefficient, $\mathrm{k}_{\mathrm{i}}$, must also be specified for the considered product. On the other hand, the gas-side mass transfer coefficient, $\beta_{\mathrm{S}, \mathrm{G}}$, may be extracted from general, non-product-specific equations.

\section{Parameter Estimation}

Because of the complex mechanisms of the bonding of moisture to solids, the equilibrium between a certain material and moist air at a prescribed temperature (sorption isotherm) can only be specified experimentally, and is usually correlated empirically. For this purpose, we employed the following empirical relationship after Raković (1987):

$X_{\text {eq }}=\left[\ln \left(1-\phi_{e q}\right) /\left(b_{1} \cdot T_{S}^{b_{2}}\right)\right]^{1 /\left(a_{1} \cdot T_{S}+a_{2}\right)}$,

with $\mathrm{T}_{\mathrm{S}}$ in $\mathrm{K}$ and:

$\phi_{\text {eq }}=\frac{p_{\mathrm{at}}}{p_{\mathrm{sat}}} \frac{\mathrm{Y}_{\mathrm{eq}}}{\mathrm{Y}_{\mathrm{eq}}+\left(1-\mathrm{Y}_{\mathrm{eq}}\right) \cdot \frac{\tilde{\mathrm{M}}_{\mathrm{v}}}{\tilde{\mathrm{M}}_{\mathrm{G}}}}$.

The same author proposed a relationship for the internal moisture transport coefficient ("drying coefficient") $k_{i}$ in Eq. (7) that accounts for the overall resistance to moisture transport in the material, namely:

$\mathrm{k}_{\mathrm{i}}=\mathrm{A}_{\mathrm{K}} \cdot\left(\frac{\mathrm{X}}{\mathrm{X}_{0}}\right)^{\mathrm{n}_{\mathrm{x}}} \cdot \mathrm{t}_{\mathrm{S}}^{\mathrm{n}_{\mathrm{T}}}$,

with $\mathrm{t}_{\mathrm{S}}$ in ${ }^{\circ} \mathrm{C}$.

All parameters of Eq. (9) $\left(a_{1}, a_{2}, b_{1}, b_{2}\right)$ and Eq. (11) $\left(\mathrm{A}_{\mathrm{K}}, \mathrm{n}_{\mathrm{T}}, \mathrm{n}_{\mathrm{X}}\right)$ were determined previously by Raković (1987). He used the classical static method of equilibration of small specimen with air over saturated 
salt solutions for measuring the sorption isotherms, that were subsequently correlated with Equation (9). Drying kinetics experiments were carried out by the same author in very thin beds (just one or two grain layers) of potato cubes with lengths of $4.0 \mathrm{~mm}, 8.0$ $\mathrm{mm}$ and $12.0 \mathrm{~mm}$, i.e., equivalent diameters of 3.22 $\mathrm{mm}, \quad 6.45 \mathrm{~mm}$ and $9.67 \mathrm{~mm}$, using air at temperatures between $60^{\circ} \mathrm{C}$ and $90^{\circ} \mathrm{C}$, moisture contents of between $0.028 \mathrm{~kg} / \mathrm{kg}$ and $0.038 \mathrm{~kg} / \mathrm{kg}$, and velocities of approximately $1 \mathrm{~m} / \mathrm{s}$. The air condition can be assumed to remain approximately constant during the flow through such thin layers, so that the parameters of Equation (11) can be derived immediately (compare with Hirschmann et al., 1998). All product-specific parameters characterizing hygroscopicity and the grain-side drying kinetics of potato are summarized in Table 1. Note that the parameters of Eq. (11), determined previously by Raković for a single potato cube length, as well as the generalized size-dependent expressions (more suitable for utilization in the simulation software), are presented.

Contrary to the previously discussed coefficients, the heat and mass transfer coefficients between grain surface and gas in a packed bed $\left[\alpha_{S, G}\right.$ and $\beta_{S, G}$ in Equations (4), (5) and (8)] do not depend on the internal structure of the product. They have been investigated extensively in the literature and generalized in the form of suitable non-dimensional correlations. While the correlations of Kunii and Levenspiel (1969) are known to give good results in the case of particles smaller than about $1 \mathrm{~mm}$ in diameter, the correlations of Ginzburg and Savina (1982):

$$
\begin{aligned}
& \mathrm{Nu}_{\mathrm{S}}=0.977 \cdot \operatorname{Pr}^{0.33} \cdot \mathrm{Re}_{\mathrm{S}}^{0.595}, \mathrm{Re}_{\mathrm{S}}>300 \\
& \mathrm{Nu}_{\mathrm{S}}=1.83 \cdot \operatorname{Pr}{ }^{0.33} \cdot \mathrm{Re}_{\mathrm{S}}^{0.485}, \quad \mathrm{Re}_{\mathrm{S}} \leq 300
\end{aligned}
$$

$$
\begin{aligned}
& \mathrm{Sh}_{\mathrm{S}}=0.977 \cdot \mathrm{Sc}^{0.33} \cdot \operatorname{Re}_{\mathrm{S}}^{0.595}, \mathrm{Re}_{\mathrm{S}}>300, \\
& \mathrm{Sh}_{\mathrm{S}}=1.83 \cdot \mathrm{Sc}^{0.33} \cdot \mathrm{Re}_{\mathrm{S}}^{0.485}, \quad \mathrm{Re}_{\mathrm{S}} \leq 300,
\end{aligned}
$$

are more accurate in the case of larger particles (grains) and have been used in the present investigation.

Parameters defining characteristics of the solids (equivalent diameter, density and specific heat capacity) and the bed (porosity of the bed) must be known accurately enough, having great influence on the heat and mass balance equations (namely $d_{S}, \rho_{S}$, $\mathrm{c}_{\mathrm{S}}$ ) through the heat and mass transfer coefficients. The values for dry potato density and heat capacity were taken from Wang and Brennan (1995). Accurate calculation of gas velocity through the packed bed of solids (interstitial velocity), highly influencing heat and mass transfer coefficients, depends on correct estimation of bed porosity $(\psi)$.

The dependencies defining the grain diameter change due to the moisture content variation can be found in literature (Ginsburg and Savina, 1982):

$$
\mathrm{d}_{\mathrm{S}}=\left[\frac{6 \cdot \mathrm{M}_{\mathrm{S}, \mathrm{d}}}{\rho_{\mathrm{S}} \cdot \pi} \cdot(1+\mathrm{X})^{0.33}\right],
$$

although a simplified dependence is used in this model:

$$
\mathrm{d}_{\mathrm{S}}=\mathrm{d}_{\mathrm{S}, \mathrm{d}} \cdot\left[\frac{\rho_{\mathrm{S}, \mathrm{d}}}{\rho_{\mathrm{S}}} \cdot(1+\mathrm{X})^{0.33}\right]
$$

Due to the highly pronounced shrinkage of the hygroscopic materials during drying, the inclusion of grain diameter change in the model is of particular

\begin{tabular}{|c|c|c|c|c|}
\hline \multicolumn{5}{|c|}{ Equilibria } \\
\hline & $a_{1}$ & $a_{2}$ & $\mathbf{b}_{1}$ & $\mathbf{b}_{2}$ \\
\hline & & & & After Eq. (9) \\
\hline & -0.00499 & 3.24433 & $1.99 \cdot 10^{-8}$ & 3.56361 \\
\hline \multicolumn{5}{|c|}{ Kinetics } \\
\hline $\mathrm{l}_{\mathrm{S}, 0}(\mathrm{~mm})$ & $\mathrm{d}_{\mathrm{S}, 0}(\mathrm{~mm})$ & $\mathbf{A}_{\mathbf{K}}$ & $\mathbf{n}_{\mathbf{X}}$ & $\mathbf{n}_{\mathrm{T}}$ \\
\hline & & \multicolumn{3}{|c|}{ After Eq. (11) } \\
\hline 4 & 3.22 & $2.540 \cdot 10^{-13}$ & 1.5020 & 5.9500 \\
\hline 8 & 6.45 & $5.634 \cdot 10^{-7}$ & 0.8018 & 1.8631 \\
\hline 12 & 9.67 & $4.266 \cdot 10^{-4}$ & 0.3645 & 0.0376 \\
\hline \multicolumn{2}{|c|}{ Size-dependent } & $\mathrm{e}^{(2.6 \cdot 1 \mathrm{~s}, 0-37.0)}$ & $-0.14 \cdot 1_{\mathrm{S}, 0}+2.0$ & $-5.43 \cdot \ln \left(1_{\mathrm{S}, 0}\right)+13.5$ \\
\hline
\end{tabular}
importance. A packed bed of hygroscopic material normally has a lower bed height at the end of the drying process compared to the initial one.

Table 1: Parameters of sorption equilibrium (Eq. (9)) and drying kinetics (Eq. (11)) for potato cubes, after Raković (1987). 


\section{Numerical Procedure}

A numerical procedure based on Patankar (1980) was used to solve the partial differential equations. Equations (2) to (6) are discretized by means of the control-volume method, i.e., the packed bed is divided by means of a vertical grid into a finite number of control volumes, as shown in Figure 2. The iterative line-by-line method is used for solving the obtained linearized algebraic equations, applying a recurrence formula during the calculation of the variable's values for every line, and following the same procedure for all the lines in one direction. This method, called the Thomas algorithm or the TDMA (TriDiagonal-Matrix Algorithm), is described in detail in the book of Patankar (1980).

The calculation starts for the first control volume and continues for the next one in the direction of gas flow after the balances represented by Equations (2) to (6) are fulfilled. The fact that there is no movement of the solids inside the packed bed $\left(u_{S}=0\right)$, i.e., the absence of "convection terms" in Equations (2) and (4), does not influence the possibility of calculating the height-dependent change of the solids' moisture content and enthalpy, but creates some problems of numerical stability. In spite of this, convergent solutions could always be obtained by appropriate selection of the underrelaxation factors (Patankar, 1980).

As Figure 2 shows, the mathematical model developed allows calculation of the local values of all state variables along the bed at any time. For the sake of presentation, time averages of the local values, as well as height-averaged values of the state variables at a specific time can be calculated.

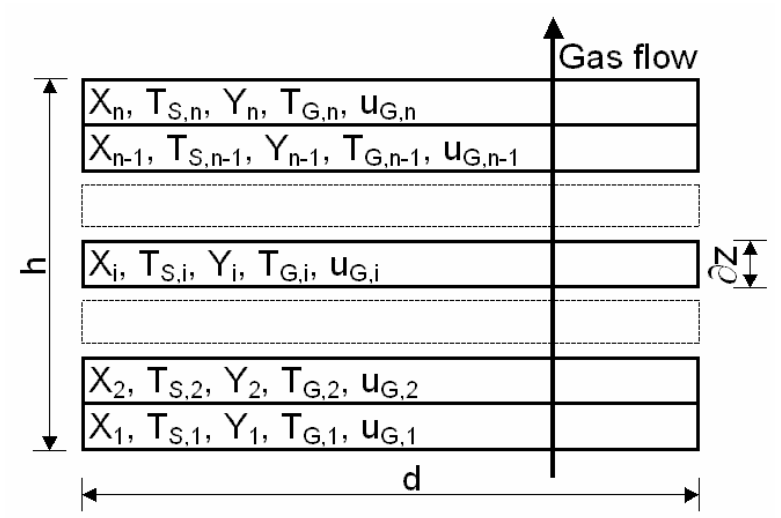

Figure 2: State variables and discretization along the height of the bed.

\section{General Software}

General "FBDRY" software has been written utilizing the Visual $\mathrm{C}++$ computer language. It is configured in the form of a usual user's environment (dialog boxes, text boxes etc.) shown in Figs. 3 to 5, with different alternatives for data input (including options for unit variation), as well as for data output.

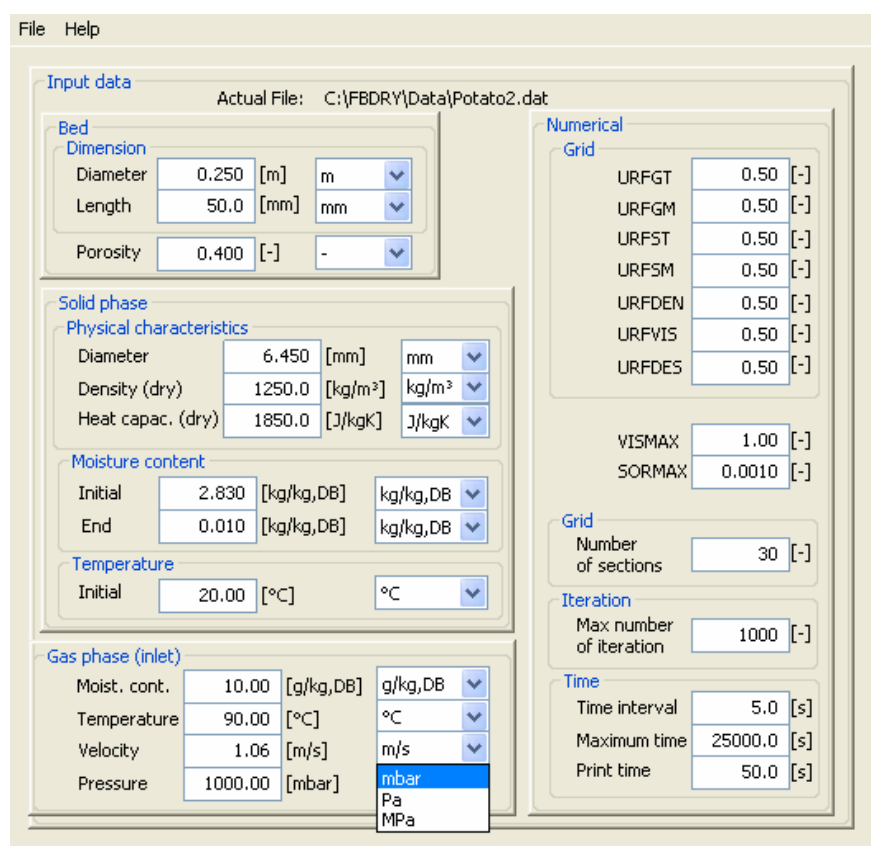

Figure 3: Inlet dialog for FBDRY software. 


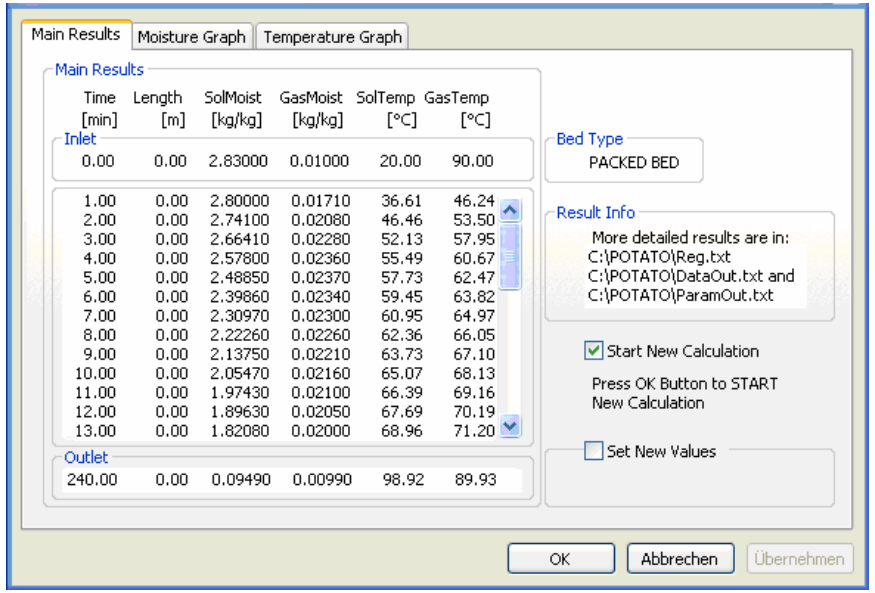

Figure 4: Outlet (text-box) dialogs for FBDRY software.

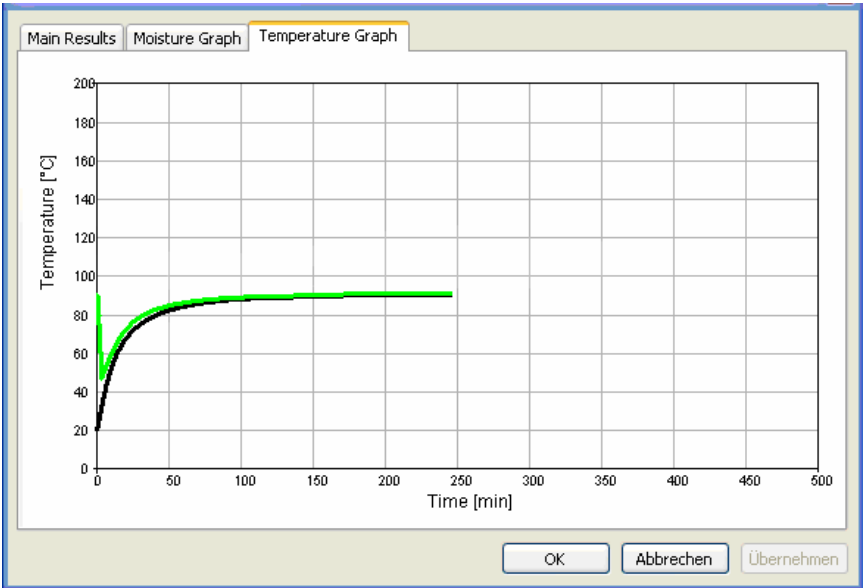

Figure 5: Outlet (temperature graph) dialog for FBDRY software.

\section{RESULTS AND DISCUSSION}

The model was validated in the past by measuring equilibria and single-grain - or equivalent (thin layer) - drying kinetics, fitting the product-dependent model parameters, simulating the operation of deepbed drying of the considered material, and comparing the calculated results with the respective experiments. This procedure has been conducted for corn grains, corn on the cob, wheat, poppy seeds, etc., see Stakić (1997) and Stakić and Tsotsas (2005). In the present work, the same type of validation has been carried out for potato. The product-dependent parameters were taken from Raković (1987) according to Table 1, and are based on the discussed thin layer measurements. The same author has also employed deeper beds with a height of up to $0.055 \mathrm{~m}$. The respective data have been systematically compared with model results in the present work, with excellent agreement. Just a few representative comparisons are presented in Figure 6. For this purpose, and as previously explained, the local values of the solids moisture content and temperature have been averaged over the bed height and are plotted against time. The agreement shows that the model can reliably describe scale-up from the thin layer to the deeper bed without any additional fitting or adaptation. The obtained drying kinetics, both experimental and numerical, show that lower equivalent grain diameters induce faster drying.

The results of numerical simulation of drying kinetics for the mentioned case are presented in Figures 7-11. For the sake of the parameter study, i.e., analysis of the influence that the drying parameters such as gas velocity, bed height, etc, have 
on the drying process, the case of one chosen particle size $(12 \mathrm{~mm})$ having an initial moisture content $\mathrm{X}_{0}=3.5$ is given first (Figs. 7 and 8). In Fig. 7, the changes with time of potato moisture content (height-averaged) and temperature (again, heightaveraged), as well as exhaust air temperature, obtained from calculation, are shown for the case of three chosen bed heights $(40,60$ and $80 \mathrm{~mm})$. The respective changes of potato moisture content and temperature (both height-averaged), and exhaust air temperature, as a function of different air velocities $(0.5,1.0$ and $1.5 \mathrm{~m} / \mathrm{s})$ are shown in Fig. 8. The highest difference between height-averaged potato temperature and exhaust air temperature is located at the beginning of the drying (period of material heating). At the end of the process, the material is almost heated up to the air exhaust temperature. These differences are more pronounced for different drying agent flow-rates (Fig. 8) than for different bed heights (Fig. 7).

It is obvious that the drying is faster for the case of smaller bed heights, because of the smaller amount of material, i.e., less moisture, to be dried. On the other hand, drying is faster in the case of higher air velocities. This is shown in terms of the necessary drying time and height-averaged final potato temperature when the target moisture content is achieved. This behavior is exactly equal to what happens in a conventional convective drying process.
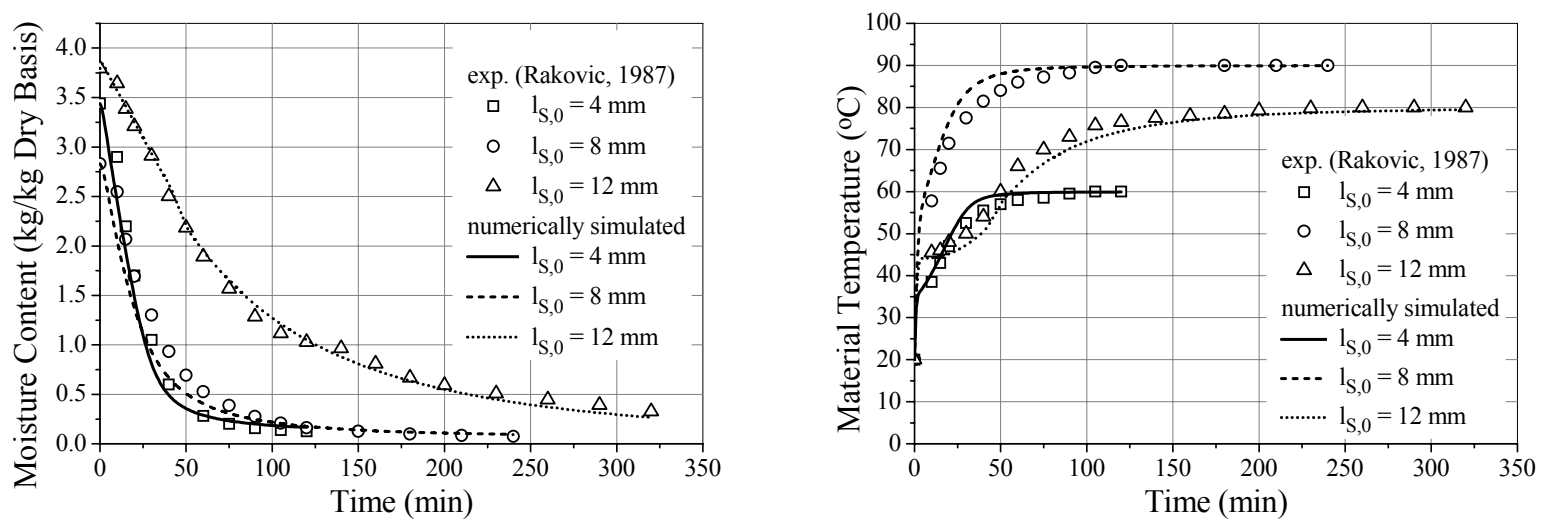

Figure 6: Comparison of simulated and experimentally determined height-averaged potato cubes drying kinetics in a packed bed;

$1_{\mathrm{S}, 0}=4 \mathrm{~mm} \quad\left(\mathrm{~d}_{\mathrm{S}, 0}=3.22 \mathrm{~mm}\right), \mathrm{X}_{0}=3.44, \mathrm{~T}_{\mathrm{S}, 0}=20^{\circ} \mathrm{C}, \mathrm{Y}_{\mathrm{in}}=0.005, \mathrm{~T}_{\mathrm{G}, \text { in }}=60.0^{\circ} \mathrm{C}, \mathrm{u}_{\mathrm{G}, \mathrm{in}}=1.05 \mathrm{~m} / \mathrm{s}, \mathrm{h}=45 \mathrm{~mm}$; $1_{\mathrm{S}, 0}=8 \mathrm{~mm} \quad\left(\mathrm{~d}_{\mathrm{S}, 0}=6.45 \mathrm{~mm}\right), \mathrm{X}_{0}=2.83, \mathrm{~T}_{\mathrm{S}, 0}=20^{\circ} \mathrm{C}, \mathrm{Y}_{\mathrm{in}}=0.01, \mathrm{~T}_{\mathrm{G}, \mathrm{in}}=90.0^{\circ} \mathrm{C}, \mathrm{u}_{\mathrm{G}, \text { in }}=1.06 \mathrm{~m} / \mathrm{s}, \mathrm{h}=50 \mathrm{~mm}$; $1_{\mathrm{S}, 0}=12 \mathrm{~mm}\left(\mathrm{~d}_{\mathrm{S}, 0}=9.67 \mathrm{~mm}\right), \mathrm{X}_{0}=3.79, \mathrm{~T}_{\mathrm{S}, 0}=20^{\circ} \mathrm{C}, \mathrm{Y}_{\mathrm{in}}=0.04, \mathrm{~T}_{\mathrm{G}, \mathrm{in}}=80.0^{\circ} \mathrm{C}, \mathrm{u}_{\mathrm{G}, \mathrm{in}}=1.01 \mathrm{~m} / \mathrm{s}, \mathrm{h}=55 \mathrm{~mm}$.
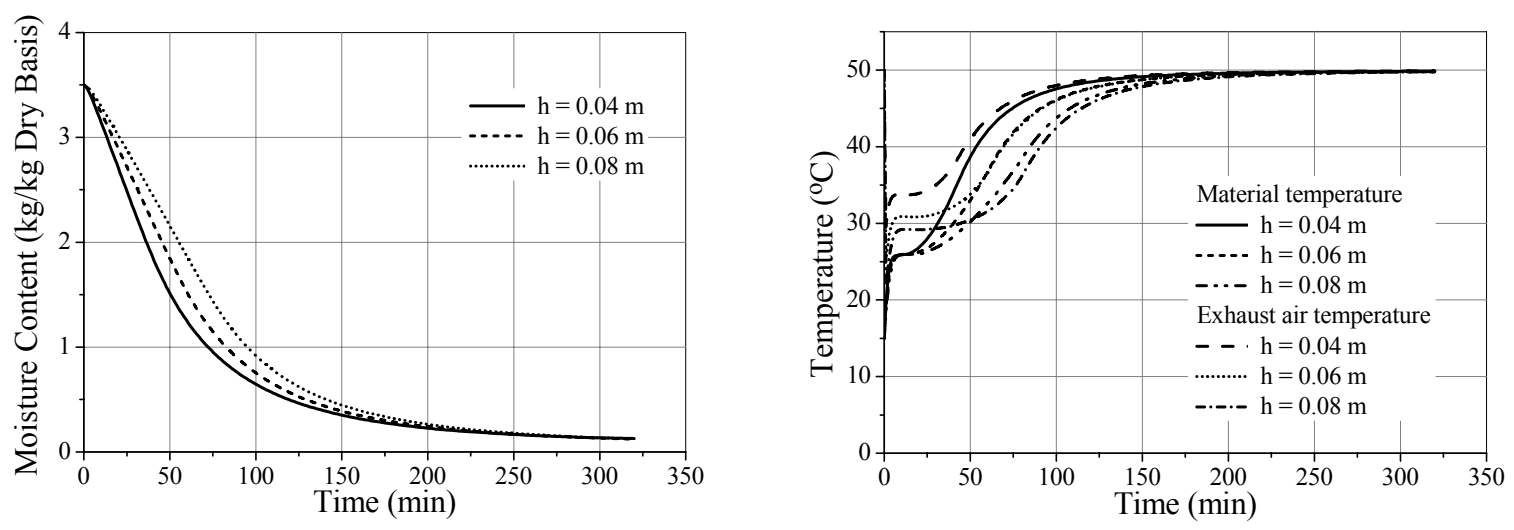

Figure 7: Effect of bed height on the simulated drying kinetics in the case of potato cubes drying in a packed bed;

$1_{\mathrm{S}, 0}=12 \mathrm{~mm}\left(\mathrm{~d}_{\mathrm{S}, 0}=9.67 \mathrm{~mm}\right), \mathrm{X}_{0}=3.5, \mathrm{~T}_{\mathrm{S}, 0}=15^{\circ} \mathrm{C}, \mathrm{Y}_{\mathrm{in}}=0.008, \mathrm{~T}_{\mathrm{G}, \text { in }}=50^{\circ} \mathrm{C}, \mathrm{u}_{\mathrm{G}, \text { in }}=1.0 \mathrm{~m} / \mathrm{s}$. 

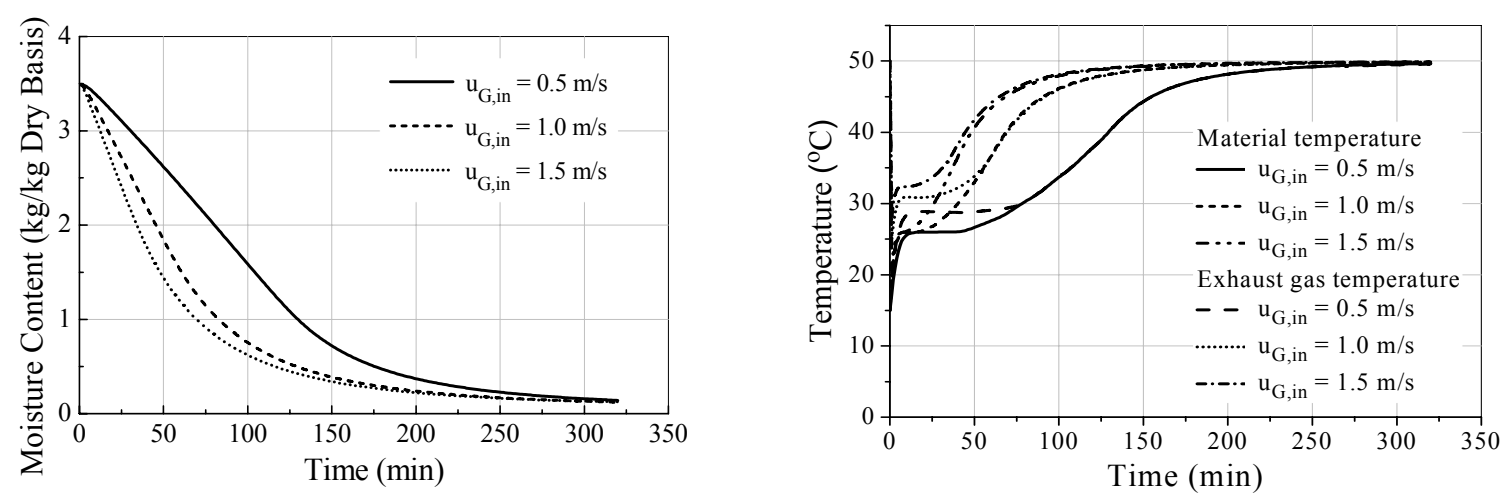

Figure 8: Effect of gas inlet velocity on the simulated drying kinetics in the case of potato cubes drying in a packed bed; $1_{\mathrm{S}, 0}=12 \mathrm{~mm}\left(\mathrm{~d}_{\mathrm{S}, 0}=9.67 \mathrm{~mm}\right), \mathrm{X}_{0}=3.5, \mathrm{~T}_{\mathrm{S}, 0}=15^{\circ} \mathrm{C}, \mathrm{Y}_{\text {in }}=0.008, \mathrm{~T}_{\mathrm{G}, \text { in }}=50^{\circ} \mathrm{C}, \mathrm{h}=0.06 \mathrm{~m}$.

In Figure 9, the changes of potato moisture content and temperature (both height-averaged) with time obtained by calculation are shown for different particle sizes $(4.0$ and $12.0 \mathrm{~mm}$ ) for the case of two bed heights (40 and $80 \mathrm{~mm})$ at a given air velocity $(1.0 \mathrm{~m} / \mathrm{s})$, as well as for two air velocities $(0.5$ and $1.5 \mathrm{~m} / \mathrm{s})$ at one bed height $(60 \mathrm{~mm})$. It is obvious that the drying is faster for the case of smaller particles, because of the superior specific surface area $\left(a_{b}\right)$, causing a more efficient moisture transport from the
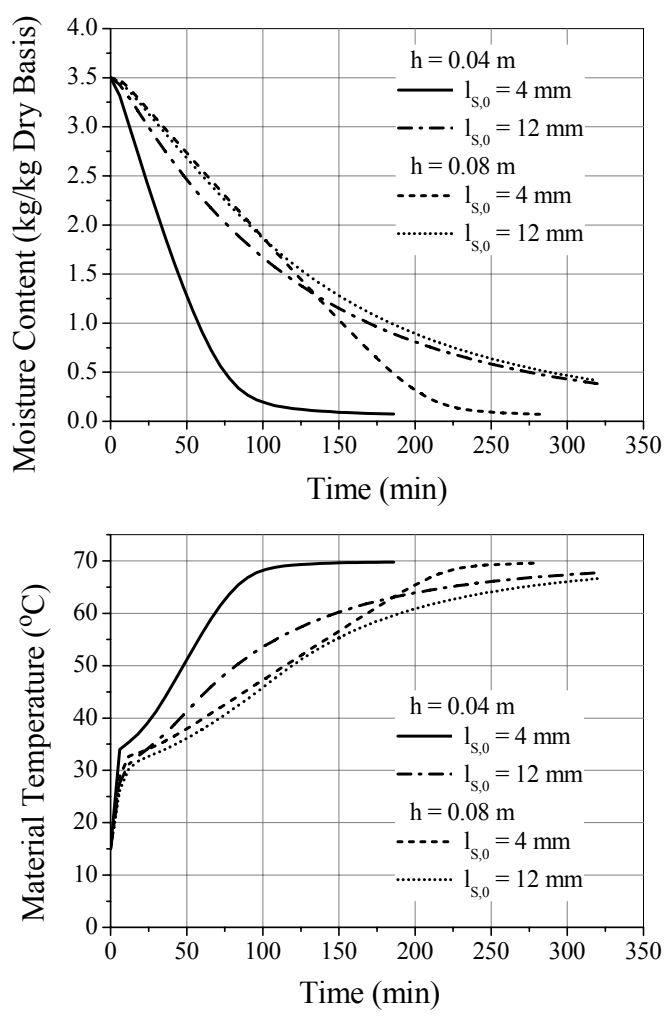

(a) $\mathrm{u}_{\mathrm{G}, \mathrm{in}}=1.0 \mathrm{~m} / \mathrm{s}$ material surface to the surrounding air, Eq. (8), and because of smaller intraparticle resistance, Eq. (11) (see also Table 1). Drying is also faster in the case of higher air velocities (Fig. 9 b) due to the higher gasto-solids heat and mass transfer coefficients. At the same time, for higher air velocities the gas flow-rate is higher, which results in a higher available drying agent capacity for vapor absorption. On the other hand, drying is slower in the case of a higher bed due to fact that more material has to be dried (Fig. 9 a).
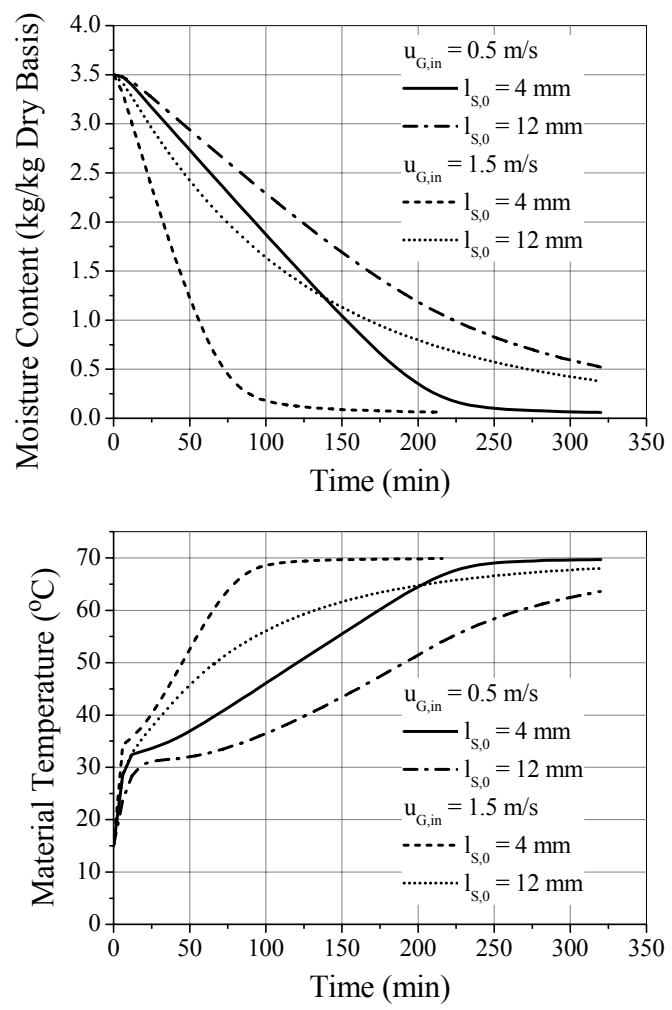

(b) $\mathrm{h}=0.06 \mathrm{~m}$

Figure 9: Effect of particle size (equivalent particle diameter) on the simulated drying kinetics in the case of potato cubes drying in a packed bed; $\mathrm{X}_{0}=3.5, \mathrm{~T}_{\mathrm{S}, 0}=15^{\circ} \mathrm{C}, \mathrm{Y}_{\mathrm{in}}=0.008, \mathrm{~T}_{\mathrm{G}, \mathrm{in}}=70^{\circ} \mathrm{C}$. 
Another aspect, not visible by means of the height-averaged values of Figs. 7 to 9, but revealed in the presentation of Figs. 10 and 11, is that the lower potato layer, being the first in contact with the fresh air, and the upper one, where the exhaust air is leaving the drying zone, have different characteristics during and at the end of drying. The lower layer dries faster than the upper one, so that the moisture content difference between two layers can be very high (depending on the applied bed heights and/or air flow-rates). The gradient in solids moisture content with respect to the packed bed

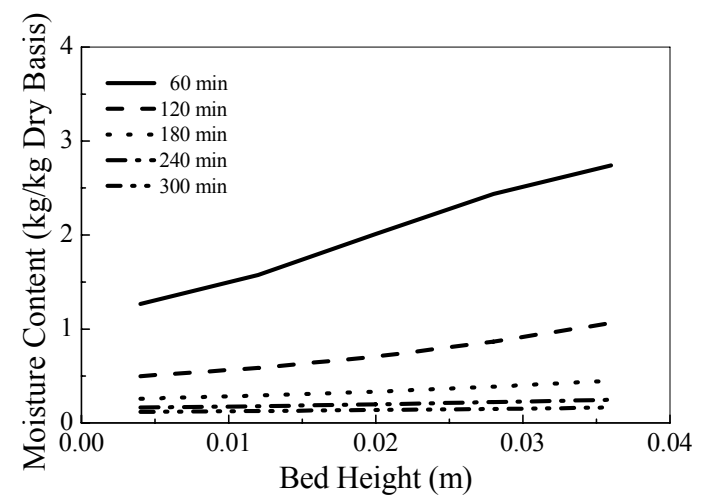

height may be somewhat decreased by alternating the drying gas flow direction from up-stream to down-stream, and vice-versa. However, much more uniform material moisture content within the dryer cannot be achieved without utilizing types of dryers that allow mixing of the solids (rotating bed, fluidized bed, vibrated fluidized bed, spouted bed, etc.). However, mixing of solids should be avoided in the case of fragile materials (possible grinding or attrition), recommending packed bed drying as the only possible solution for this delicate type of material.

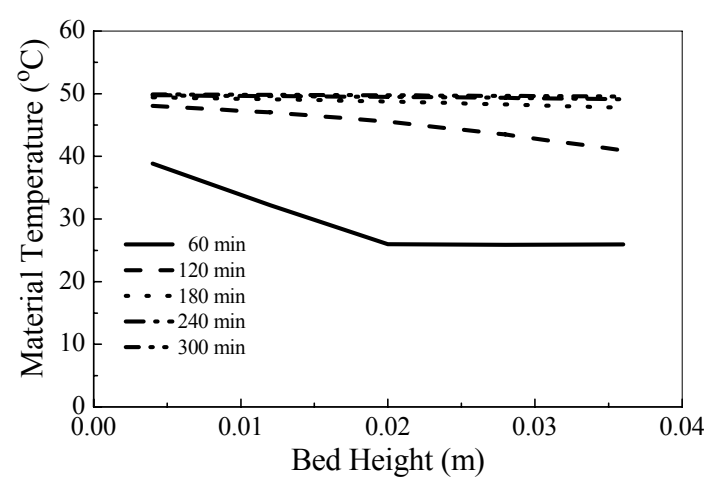

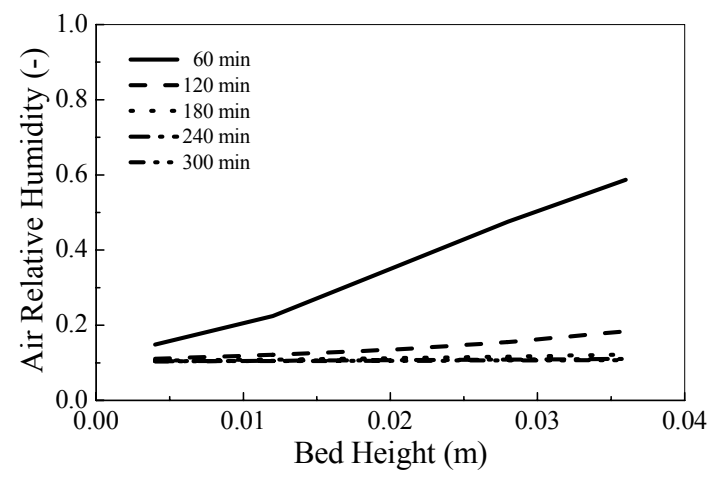

Figure 10: Change of potato moisture content, potato temperature and air relative humidity over the bed height during the convective drying of potato cubes in a packed bed;

$\mathrm{l}_{\mathrm{S}, 0}=12 \mathrm{~mm}\left(\mathrm{~d}_{\mathrm{s}, 0}=9.67 \mathrm{~mm}\right), \mathrm{X}_{0}=3.5, \mathrm{~T}_{\mathrm{S}, 0}=15^{\circ} \mathrm{C}, \mathrm{T}_{\mathrm{G}, \mathrm{in}}=50^{\circ} \mathrm{C}, \mathrm{Y}_{\mathrm{in}}=0.008, \mathrm{~h}=0.04 \mathrm{~m}, \mathrm{u}_{\mathrm{G}, \text { in }}=0.5 \mathrm{~m} / \mathrm{s}$.
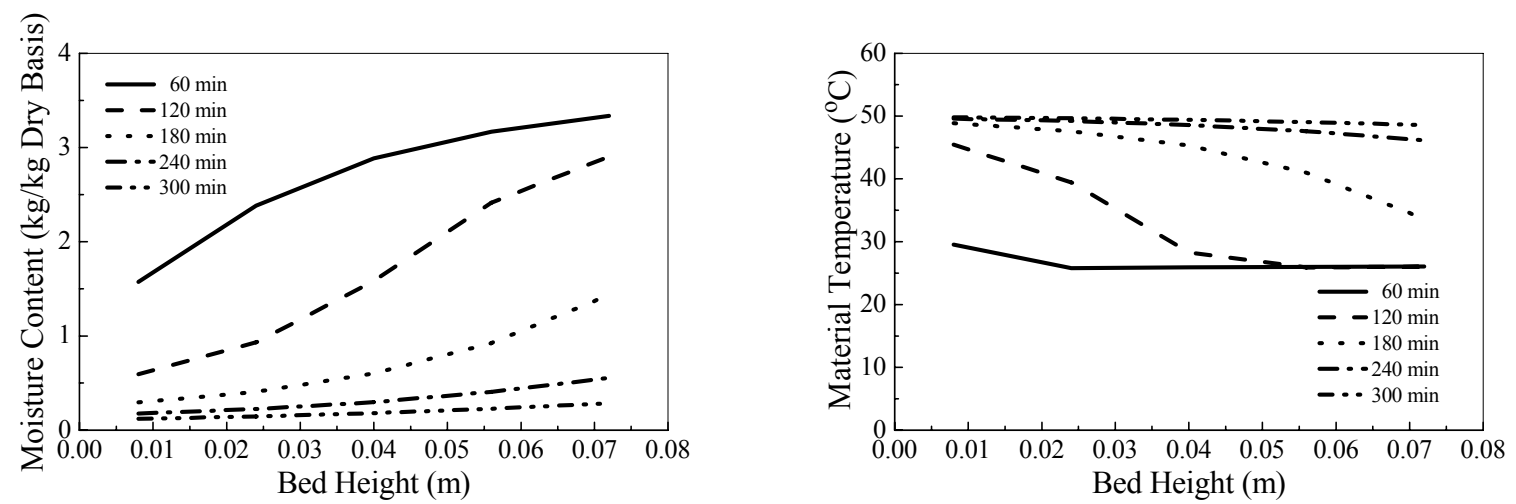


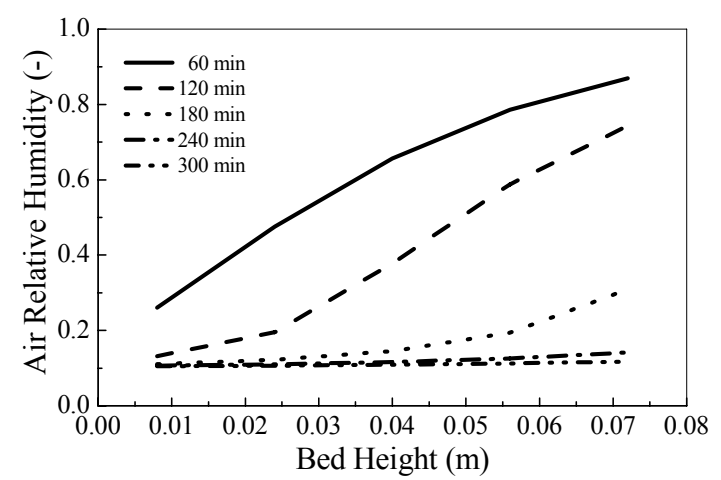

Figure 11: Results similar to those of Fig. 10, however for $h=0.08 \mathrm{~m}$ and $\mathrm{u}_{\mathrm{G}, \text { in }}=1.0 \mathrm{~m} / \mathrm{s}$.

\section{CONCLUSIONS}

Selected results obtained on the basis of a model for the convective drying process of a hygroscopic material (potato cubes) in a packed bed are presented in this paper.

Comparison of the corresponding parameters for the drying process obtained by calculations on the basis of the model developed and from the experimental investigation (for the applied parameter range) showed good agreement. The model has a lot of potential for predicting the relevant parameters of convective drying in a packed bed.

The values of time- and height-averaged parameters, as well as the variation of parameters along the bed height at any moment of time, can be calculated reliably.

On the basis of the calculated values of the corresponding parameters, a clear image of the process itself can be obtained, as well as an overview of the advantages and disadvantages of a specific design (deep or shallow bed, high or low temperature drying, with or without gas flow recirculation, etc.) making the decisions about the choice of dryer type simpler. As an example, the convection dryer's efficiency can be improved by recycling some of the moist exhaust air - together with its energy (in the form of waste heat) - back to the dryer inlet. Recycling the exhaust air increases the humidity in the dryer. This, in turn, requires a higher operating temperature and results in a higher final product temperature than in a completely open-circuit convection-drying operation. The most favorable decision can be made by using the calculated values obtained from the simulation model developed.

\section{NOMENCLATURE} $\mathrm{a}_{1}, \mathrm{a}_{2} \quad$ coefficient with dimensions
as defined by Equation (9)

\begin{tabular}{|c|c|}
\hline$a_{b}$ & bed specific surface area \\
\hline $\mathrm{A}_{\mathrm{K}}$ & $\begin{array}{l}\text { coefficient with dimensions } \\
\text { as defined by Equation (11) }\end{array}$ \\
\hline $\mathrm{b}_{1}$ & $\begin{array}{l}\text { coefficient with dimensions } \\
\text { as defined by Equation (9) }\end{array}$ \\
\hline $\mathrm{b}_{2}$ & exponent of Equation (9) \\
\hline $\mathrm{c}$ & specific heat capacity \\
\hline $\mathrm{d}$ & diameter \\
\hline $\mathrm{h}$ & bed height \\
\hline $\mathrm{k}_{\mathrm{i}}$ & $\begin{array}{l}\text { internal moisture transport } \\
\text { coefficient }\end{array}$ \\
\hline 1 & length \\
\hline M & mass \\
\hline$\tilde{M}$ & molecular mass \\
\hline $\mathrm{n}_{\mathrm{X}}, \mathrm{n}_{\mathrm{T}}$ & exponents of Equation (11) \\
\hline $\mathrm{p}$ & pressure \\
\hline $\mathrm{r}$ & heat of evaporation \\
\hline $\mathrm{S}_{\mathrm{M}}$ & mass source \\
\hline $\mathrm{t}$ & temperature \\
\hline $\mathrm{T}$ & temperature \\
\hline $\mathrm{u}$ & velocity \\
\hline$\dot{\mathrm{V}}$ & volumetric flow-rate \\
\hline$X$ & $\begin{array}{l}\text { material moisture content } \\
\text { (dry basis) }\end{array}$ \\
\hline $\mathrm{Y}$ & $\begin{array}{l}\text { gas moisture content } \\
\text { (dry basis) }\end{array}$ \\
\hline $\mathrm{z}$ & axial coordinate \\
\hline
\end{tabular}

$\mathrm{m}^{2} \cdot \mathrm{m}^{-3}$ $(-)$ $\mathrm{J} \cdot \mathrm{kg}^{-1} \cdot \mathrm{K}^{-1}$ $\mathrm{m}$ $\mathrm{m}$ $\mathrm{s}^{-1}$ $\mathrm{m}$ $\mathrm{kg} \cdot \mathrm{kmol}^{-1}$ $\mathrm{Pa}$ $\mathrm{J} \cdot \mathrm{kg}^{-1}$ $\mathrm{kg} \cdot \mathrm{s}^{-1}$ ${ }^{\circ} \mathrm{C}$ $\mathrm{m} \cdot \mathrm{s}^{-1}$ $\mathrm{m}^{3} \cdot \mathrm{s}^{-1}$

$\mathrm{m}$

\section{Greek Symbol}

$\begin{array}{ll}\alpha & \text { heat transfer coefficient } \\ \beta & \text { mass transfer coefficient } \\ \delta & \text { diffusion coefficient } \\ \eta & \text { dynamic viscosity } \\ \lambda & \text { thermal conductivity } \\ \rho & \text { density } \\ \phi & \text { air relative humidity } \\ \psi & \text { bed porosity } \\ \tau & \text { time }\end{array}$

$\mathrm{W} \cdot \mathrm{m}^{-2} \cdot \mathrm{K}^{-1}$
$\mathrm{~m} \cdot \mathrm{s}^{-1}$
$\mathrm{~m}^{2} \cdot \mathrm{s}^{-1}$
$\mathrm{~Pa} \cdot \mathrm{s}$
$\mathrm{W} \cdot \mathrm{m}^{-1} \cdot \mathrm{K}^{-1}$
$\mathrm{~kg} \cdot \mathrm{m}^{-3}$
$(-)$
$(-)$
$\mathrm{s}$ 


\section{Dimensionless Criteria}

$\mathrm{Nu}_{\mathrm{S}} \quad$ Nusselt number, $\alpha_{\mathrm{S}, \mathrm{G}} \cdot \mathrm{d}_{\mathrm{S}} / \lambda_{\mathrm{G}}$

Pr Prandtl number, $c_{\mathrm{G}} \cdot \eta_{\mathrm{G}} / \lambda_{\mathrm{G}}$

$\operatorname{Re}_{\mathrm{S}} \quad$ Reynolds number, $\mathrm{d}_{\mathrm{S}} \cdot \mathrm{u}_{\mathrm{G}} \cdot \rho_{\mathrm{G}} / \eta_{\mathrm{G}}$

Sc Schmidt number, $\eta_{\mathrm{G}} /\left(\rho_{\mathrm{G}} \cdot \delta_{\mathrm{v}}\right)$

$\mathrm{Sh}_{\mathrm{S}} \quad$ Sherwood number, $\beta_{\mathrm{S}, \mathrm{G}} \cdot \mathrm{d}_{\mathrm{S}} / \delta_{\mathrm{v}}$

\section{Subscripts}

$\begin{array}{ll}\text { at } & \text { atmospheric } \\ \text { b } & \text { bed } \\ \text { d } & \text { dry } \\ \text { eq } & \text { equilibrium } \\ \text { G } & \text { gas } \\ \text { i } & \text { internal } \\ \text { in } & \text { inlet } \\ \text { S } & \text { solids } \\ \text { sf } & \text { surface } \\ \text { sat } & \text { saturated } \\ \text { v } & \text { vapor } \\ \text { w } & \text { water } \\ \text { 0 } & \text { initial, superficial }\end{array}$

\section{REFERENCES}

Bakker-Arkema, F. W., Lerew, L. E., Brook, R. C., Brooker, D. B., Energy and capacity performance evaluation of grain dryers. ASAE Paper, No. 78 3523 (1978).

Becker, H. A., Gupta, K. L., Ellsworth, J. H., Mathematical model for deep-bed grain drying, Paper presented at 21st Canadian Chemical Engineering Conferences (1971).

Dalpasquale, V. A., Sperandio, D., Monken, S., Luiz, H., Kolling, E., Fixed-bed drying simulation of agricultural products using a new backward finite difference scheme. Applied Mathematics \& Computation, 200, No. 2, p. 590-595 (2008).

Douglas, P. L., Jones, J. A. T., Mallick, S. K., Modeling and simulation of crossflow grain dryers, Part I: Model development. Trans. IChemE, 72, p. 325-331 (1994).

Ginzburg, A. S., Savina, I. M., Moist transport characteristics of food products. Handbook, Light and Food Industry, Moscow (1982).

Herman, E., Rodriguez, C., Garcia, M. A., Mathematical modeling for fixed-bed drying considering heat and mass transfer and interfacial phenomena. Drying Technology, 19, No. 9, p. 2343-2362 (2001).

Hirschmann, C., Fyhr, C., Tsotsas, E., Kemp, I. C., Comparison of two basic methods for measuring drying curves: Thin layer method and drying channel. Proceedings of the International Drying Symposium (IDS '98), Halkidiki, p. 224-231 (1998).

Istadi, I., Sitompul, J. P., A comprehensive mathematical and numerical modeling of deep-bed grain drying. Drying Technology, 20, No. 6, p. 11231142 (2002).

Izadifar, M., Baik, O-D., Simonson, C. J., Modeling of the packed bed drying of paddy rice using the local volume averaging (LVA) approach. Food Research International, 39, No. 6, p. $712-720$ (2006).

Keey, R. B., Drying: Principles and Practice. Pergamon Press, Oxford (1972).

Kunii, D. and Levenspiel, O., Fluidization Engineering. 1st Ed.; John Wiley \& Sons, Inc.: New York (1969).

Luikov, A. V., Drying theory. Energy, Moscow (1968).

Milojević, D. and Stefanović, M., Convective drying of thin and deep beds of grain. Chem. Eng. Commun, 13, No. 4-6, p. 261-269 (1982).

Patankar, S. V., Numerical heat transfer and fluid flow, Hemisphere P.C., New York (1980).

Raković, A., Analysis of real materials drying kinetics. Master's Thesis, Belgrade University, Faculty of Mechanical Engineering, Belgrade (1987). (in Serbian).

Sitompul, J. P., Istadi, I., Widiasa, I. N., Modeling and simulation of deep-bed grain dryers. Drying Technology, 19, No. 2, p. 269-280 (2001).

Sitompul, J. P., Istadi, I., Sumardiono, S., Modeling and simulation of momentum, heat and mass transfer in a deep-bed grain dryers. Drying Technology, 21, No. 2, p. 217-229 (2003).

Stakić, M., Numerical Simulation of Real Materials Convective Drying in Fixed Bed. Thermal Science, 1, No. 2, p. 59-70 (1997).

Stakić, M. and Tsotsas, E., Model-Based Analysis of Convective Grain Drying Process. Drying Technology, 23, No. 9-11, p. 1895-1908 (2005).

Thompson, T. L., Simulation for optimal grain dryer design. Transaction of the ASAE, 1, No. 10, p. 844-848 (1970).

van Meel, D. A., Adiabatic Convection Batch Drying with Recirculation of Air. Chem. Eng. Sci., No. 9, p. 36-44 (1958).

Wang, D. -C., Fon, D. -S., Fang, W., Development of SAPGD - A simulation software regarding grain drying. Drying Technology, 22, No. 3, p. 609-625 (2004).

Wang, N. and Brennan, J. G., Density and Porosity of Potato during Dehydration. Journal of Food Engineering, No. 24, p. 61-76 (1995).

Wang, N. and Brennan, J. G., A Mathematical Model of Simultaneous Heat and Moisture Transfer during Drying of Potato. Journal of Food Engineering, No. 24, p. 47-60 (1995). 